\title{
A postura educativa de O Tico-Tico: uma análise da primeira revista brasileira de histórias em quadrinhos $^{1}$
}

Waldomiro Vergueiro

Professor titular da Escola de Comunicações e Artes da Universidade de São Paulo ECA/USP, onde é coordenador do Observatório de Histórias em Quadrinhos.

E-mail: wdcsverg@usp.br

Roberto Elísio dos Santos

Jornalista, com pós-doutorado em Comunicação pela Escola de Comunicações e Artes da Universidade de São Paulo - ECA/USP, professor da Universidade Municipal de São Caetano do Sul, vice-coordenador do Observatório de Histórias em Quadrinhos da ECA/USP e pesquisador do Núcleo de Estudos da Comunicação e Inovação.

E-mail: robelisio@imes.edu.br

Resumo: Este trabalho discute a produção da revista $O$ Tico-Tico, publicação de quadrinhos de mais longa duração no Brasil. A revista, que teria completado 100 anos em outubro de 2005, caracterizou-se por uma postura didático-pedagógica e pela disseminação de produtos quadrinhísticos genuinamente nacionais, dando oportunidade para a atuação de dezenas de desenhistas brasileiros e propiciando o aparecimento de diversos personagens de histórias em quadrinhos. Na década de 1960, desgastada pelo tempo e sofrendo a concorrência da televisão, a revista encerrou suas atividades, ficando na lembrança de seus leitores por sua abnegação a um modelo de educação para a infância que privilegiava o civismo, os bons costumes e a religiosidade.

Palavras-chave: histórias em quadrinhos, publicações brasileiras, revistas educativas.
Abstract: This article discusses the production of the magazine O Tico-Tico, the longest publication of comics in Brazil. The magazine, which would have been 100 years old in October 2005, was characterized by a didactic-pedagogic position and by the dissemination of genuinely Brazilian comics products, giving to dozens of Brazilian artists the possibility of working on comics and also making possible the creation of several comic book characters. In the 1960s, out of date and suffering the competition of television, the magazine ceased its publication, remaining in the memory of its readers by its abnegation to a model of children education that puts the civism, the good morals and the religiosity in the first place.

Keywords: comics, Brazilian publications, educational magazines.
Recebido: 19/09/2006 Aprovado: 17/10/2007

1. Este trabalho foi desenvolvido como atividade do Núcleo de Pesquisas de Histórias em Quadrinhos da ECA-USP. 
2. SODRÉ, Nelson Werneck. História da imprensa no Brasil. 3. ed. São Paulo: Martins Fontes, 1983, p. 19

3. MELO, José Marques de. Para uma leitura crítica da comunicação. São Paulo: Paulinas, 1985 p. 117-118.

4. SODRÉ, op. cit., p. 202-203.
No período colonial, o governo português impediu a implantação da imprensa no Brasil. Somente com a transferência da corte de Portugal para o Rio de Janeiro, em 1808, jornais e outros veículos impressos começaram a ser produzidos. Segundo Sodré, "a imprensa surgiria, finalmente, no Brasil - e ainda desta vez, a definitiva, sob proteção oficial, mais do que isso: por iniciativa oficial -, com o advento da corte de D. João"2.

Contudo, o alto índice de analfabetismo da população e a predominância de áreas rurais limitaram os efeitos dos meios impressos em um país de dimensões continentais. De acordo com Melo,

[...] o retardamento na implantação da imprensa [no Brasil] deveu-se menos aos fatores políticos conjunturais apontados pela história oficial do que à conjugação de uma série de fatores socioculturais que refletiriam a estrutura econômica do projeto colonial luso que aqui prosperou ${ }^{3}$.

Ao longo do século XIX, o desenvolvimento do Rio de Janeiro facultou a disseminação de publicações impressas. As divergências políticas entre liberais, conservadores, republicanos, monarquistas, abolicionistas e latifundiários escravistas iam para os jornais como editoriais ou crônicas satíricas. Com o aprimoramento das técnicas de impressão, tornou-se possível a edição de ilustrações, caricaturas, charges e narrativas ilustradas, o embrião da nossa história em quadrinhos.

Para Sodré:

As inovações tecnológicas que permitiram o advento da gravura e, conseqüentemente, da caricatura, na imprensa brasileira, deram-lhe considerável impulso, asseguraram novas condições à crítica e ampliaram a sua influência. Nesse sentido, o humorismo foi precursor da caricatura, que apareceu quando as técnicas de gravação permitiram conjugá-lo à atração visual do desenho e da imagem ${ }^{4}$.

Um dos pioneiros das narrativas gráficas seqüenciais no Brasil foi o ítalobrasileiro Ângelo Agostini, editor, jornalista e ilustrador de títulos como Diabo Coxo, Vida Fluminense, Revista Ilustrada e Dom Quixote. De sua imaginação saíram os primeiros personagens fixos dos quadrinhos nacionais, como, por exemplo, Nhô Quim (1869) e Zé Caipora (1888). Na primeira década do século XX, participou da revista $O$ Tico-Tico, para a qual criou o primeiro logotipo, histórias em quadrinhos, capas e ilustrações.

A revista $O$ Tico-Tico é um marco na indústria editorial brasileira, sendo a mais longeva publicação periódica dirigida à infância no País, editada por 56 anos. Foi também a primeira revista a trazer regularmente histórias em quadrinhos, em uma época em que a linguagem gráfica seqüencial começava a dar seus primeiros passos, enfrentando pressões de todos os tipos, principalmente quanto a seus méritos educacionais.

A tudo a revista brasileira respondeu com uma postura firme em relação a seus objetivos didático-pedagógicos, mantendo-se arraigada à missão de entreter, informar e formar, de maneira sadia, a criança brasileira. Este artigo, além de fazer uma homenagem a tão importante publicação, busca também avaliar sua contribuição para o desenvolvimento da indústria quadrinhística brasileira. 


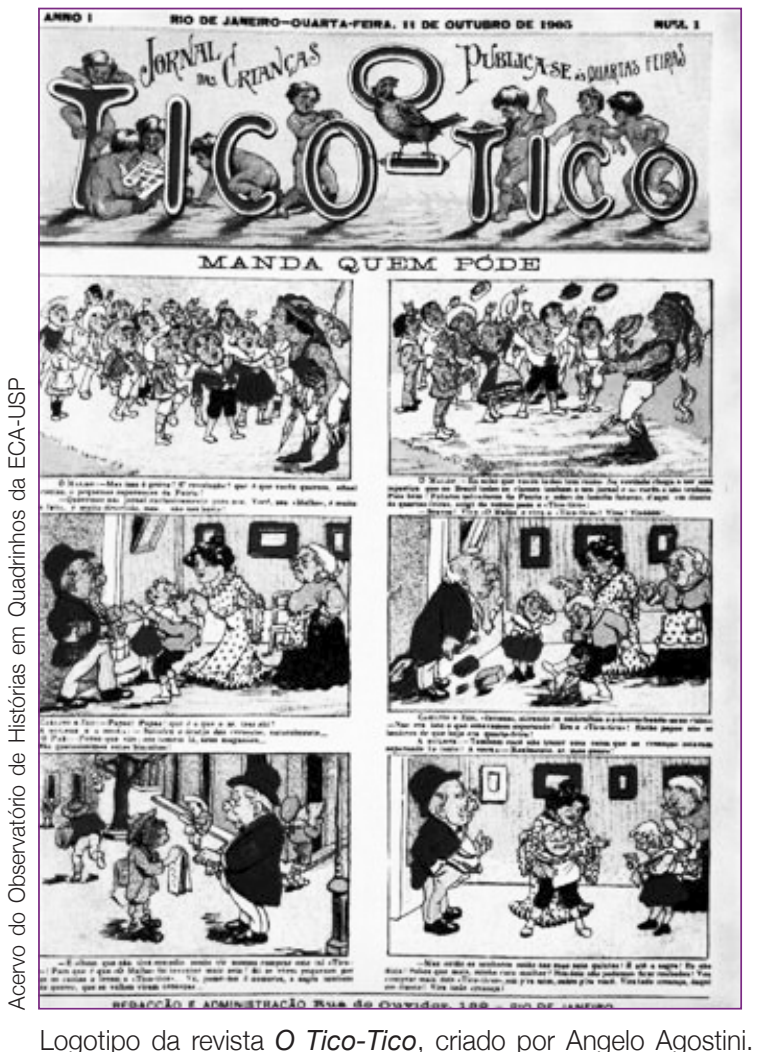

\section{O PROJETO EDITORIAL}

Idealizada por Renato de Castro, juntamente com Cardoso Júnior e Manoel Bonfim, a revista $O$ Tico-Tico foi apresentada a Luís Bartolomeu de Souza e Silva, dono da Sociedade Anônima O Malho, que acatou a idéia e ajudou a moldá-la segundo o formato de outras publicações da época, principalmente a revista francesa La Semaine de Suzette (1905-1960). O acerto da nova publicação infantil confirmou-se pela recepção do público.

Desde o início, a revista destacou-se por uma seleção de seções, apresentando matérias com teor informativo, educativo, cívico e moral. A variedade foi, talvez, sua maior característica, dando conta dos diversos aspectos da vida social necessários ao desenvolvimento das crianças. Elaborada em tom carinhoso, com linguagem coloquial e preciosismo lingüístico, acreditava que o avanço do País dependia do compromisso com a educação das futuras gerações, ampliando seu acesso às benesses da civilização letrada. Com base nesse objetivo é que foi organizado seu projeto editorial.

Várias gerações tiveram acesso a essa revista, obtendo o mesmo nível de entretenimento e informação. Além disso, seus editores preocuparam-se em cultivar boas relações com o público, tornando-o participante de sua proposta editorial. A cada mudança de rumo, a direção elaborava um texto explicativo, de forma a quebrar o impacto negativo que isso poderia gerar na comunidade ${ }^{5}$. Pode-se dizer que a publicação foi marcada pela sensibilidade de mercado, com

5. A esse respeito, ver ROSA, Zita de Paula. O Tico-Tico: meio século de ação recreativa e pedagógica. Bragança Paulista: EDUSF, 2002. 
seus organizadores antecipando-se em alguns anos às propostas de marketing defendidas décadas depois.

\section{AS HISTÓRIAS EM QUADRINHOS}

Nas histórias em quadrinhos, a revista $O$ Tico-Tico publicou inicialmente produções norte-americanas e européias. Da produção norte-americana, inclusive, veio seu principal destaque, no Brasil batizado como Chiquinho, mas originalmente conhecido como Buster Brown. Criação de Richard Felton Outcault, o garoto, originalmente de classe alta, aqui adquiriu modos do povo, vivendo aventuras ao lado de um menino de nossa realidade social mais popular, o Benjamin, que era de origem africana - personagem criado por um dos autores brasileiros que continuaram a obra de Outcault no País. Esse autor, Luis Gomes Loureiro, foi apenas o primeiro artista nacional a trabalhar com tal personagem, fazendo com que este adquirisse características próprias da cultura brasileira.

Em seu conjunto, Augusto Rocha, Alfredo Storni, Paulo Afonso, Oswaldo Storni e Miguel Hochmann, autores brasileiros que se dedicaram ao personagem Chiquinho, transformaram uma criação sem muita graça e com proposta elitista de público em uma figura pulsante, elétrica, que agradava aos leitores e fazia com que estes se identificassem com ela. Não admira que, durante vários anos, os leitores imaginassem ser Chiquinho um personagem de quadrinhos produzido no Brasil ${ }^{6}$.

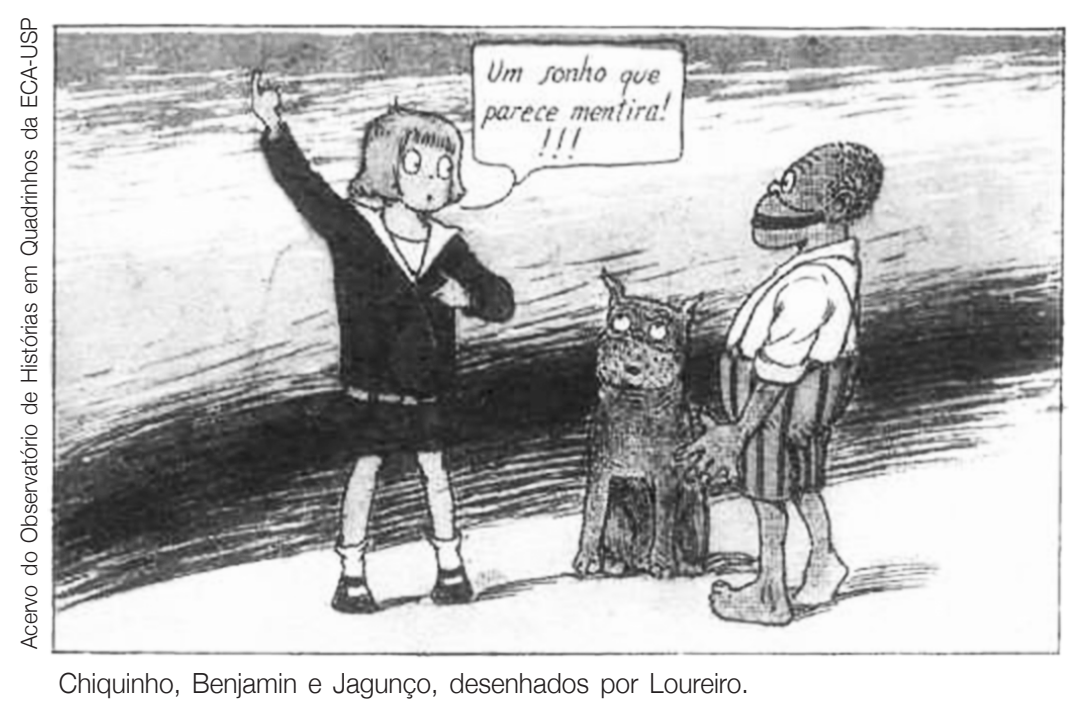

6. Ver COTRIM, Álvaro. Era uma vez um... TicoTico. Cultura, Brasília, v. 4 , n. 15 , p. $82-91$, dez. 1974; CIRNE, Moacy. História e crítica dos quadrinhos brasileiros. Rio de Janeiro: Ed. Europa/ Funarte, 1990.

Vários outros personagens, tanto estrangeiros como brasileiros, foram publicados regularmente na revista. Destacando-se, entre os primeiros, Mickey Mouse, em histórias desenhadas por Ub Iwerks e por Floyd Gottfredson; Krazy Kat, de George Herriman; Popeye, de Elsie Chrisler Segar; Gato Félix, de Pat Sullivan; Mutt e Jeff, de Bud Fisher; Little Nemo in Slumberland, de Winsor 
McCay etc. ${ }^{7}$. Entre os brasileiros, figuras como Lamparina, de J. Carlos; Kaximbown, de Max Yantok; Bolinha e Bolonha, de Nino Borges; Zé Macaco e Faustina, de Alfredo Storni; Pirolito, de Fritz (Anísio Oscar Mota); Tinoco, o caçador de feras, de Théo; João Charuto, de Edmundo Rodrigues; e Réco-Réco, Bolão e Azeitona, de Luis Sá, para mencionar apenas alguns ${ }^{8}$.

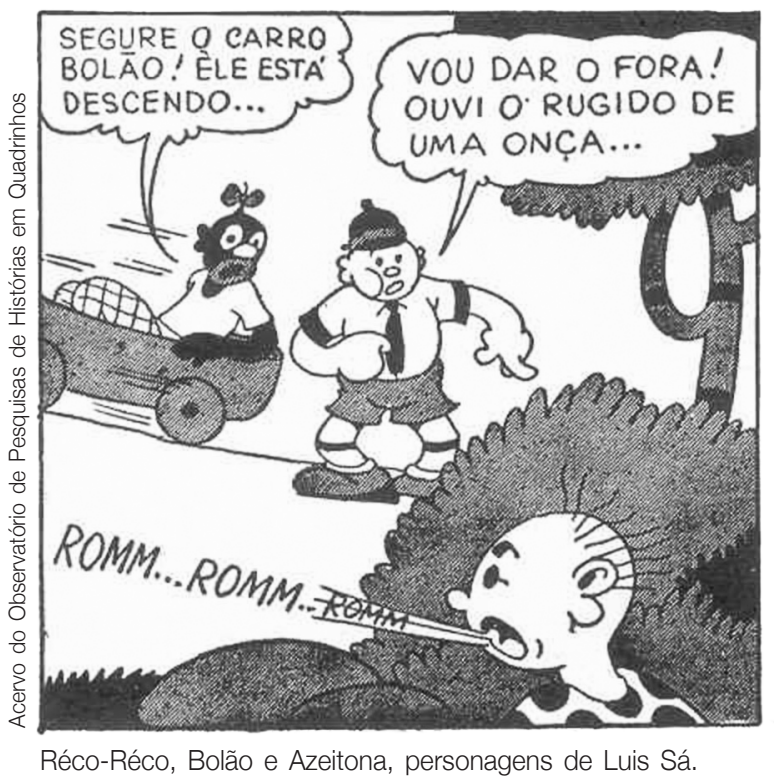

Além de séries com personagens fixos, a revista também trazia quadrinhos com finalidades instrutivas ou de informação, contendo episódios da história brasileira, aspectos de nossa cultura ou biografias de figuras da cena política e econômica nacional, como O descobrimento do Brasil, História ilustrada - Páginas relembradas e Figuras magnificas, todos por Leônidas Freire; A vida de Floriano Peixoto, texto de A. Plessen, com ilustrações de Cícero Valladares, e Histórias do tempo da escravidão, por Ângelo Agostini'.

\section{A DIMENSÃO CULTURAL}

Muitas páginas da revista $O$ Tico-Tico eram introduzidas por produções de literatura, pequenos contos ou histórias para o público infantil, além de romances de folhetim, poesias, crônicas, reflexões sobre a realidade brasileira e conselhos para os jovens leitores. Algumas eram traduções ou adaptações de publicações estrangeiras em capítulos, como as obras de Mark Twain, Robert Louis Stevenson, Julio Verne, Cervantes, Shakespeare, Jonathan Swift, Daniel Defoe, entre outros. Os contos de fadas e muitas lendas brasileiras também foram constantes na revista.

A revista tinha redatores regulares que trabalhavam para a Sociedade Anônima O Malho. Entre estes, dois nomes se destacam: Carlos Manhães e Eustórgio Wanderley. O primeiro, redator-chefe da revista de 1926 até 1939, trouxe novos desenhistas para sua equipe, buscou compatibilizar as matérias
7. MOYA, Álvaro de. O Tico-Tico: marco de nossas publicações infantis. In: Vapt-Vupt. São Paulo: Clemente \& Germani Editora, 2003. p. 106-110.

8. O TICO-TICO: uma revista impressa na lembrança. São Paulo: SESC, 2003-2004.

9. O TICO-TICO: edição comemorativa do 50aniversário. Rio de Janeiro: O Malho, 1955. 
da publicação com o currículo escolar, foi responsável pela introdução de uma dinâmica própria à publicação e pela inclusão dos personagens de quadrinhos popularizados no cinema de animação, como Mickey e o Gato Félix. Já Eustórgio Wanderley, utilizando diversos pseudônimos, escreveu poesias, contos, crônicas, conselhos aos leitores etc. Permaneceu praticamente até o final da trajetória da revista, respondendo por diversas seções, dentre as quais sobressai a Correspondência do Dr. Sabetudo ${ }^{10}$.

Muitos escritores de renome participaram da seção literária de O Tico-Tico. Destacaram-se Josué Montello, Leonor Posada, Osvaldo Orico, José Lins do Rego, Bastos Tigre, Olavo Bilac, Cardoso Júnior, Coelho Neto, Murilo Araújo, Catulo da Paixão Cearense, Malba Tahan, Humberto de Campos, Arnaldo Niskier e Gustavo Barroso, entre outros. Sérgio Buarque de Holanda colaborou com a revista antes de seu reconhecimento como autor intelectual de obras clássicas da cultura brasileira ${ }^{11}$.

A preocupação dos editores com a produção literária gerou uma coleção de livros infantis, a Biblioteca Infantil d'O Tico-Tico, em formato grande e ricamente ilustrada; teve títulos como Contos da Mãe Preta, de Osvaldo Orico; Minha babá, de J. Carlos; Papae, de Juracy Camargo; Pinga-fogo, o detetive errado, de Luis Sá; O circo dos animais, de Gaspar Coelho e Um menino de coragem, de Leão Padilha. Além da divulgação de obras literárias, eles também procuravam incentivar a produção de seus leitores, promovendo concursos de contos e publicando os trabalhos dos vencedores. Muitos jovens sentiram o despertar de sua vocação literária por meio das colaborações nos concursos da revista.

Outras áreas do panorama artístico também encontravam espaço na revista O Tico-Tico, como poesias, partituras e letras de músicas, textos sobre cinema e peças de teatro curtas que poderiam ser encenadas pelos próprios leitores. $\mathrm{Na}$ área musical, o colaborador mais freqüente da publicação foi Eustórgio Wanderley; em alguns números era possível encontrar a seção Os Músicos Famosos, que abordava a vida e obra de artistas como Handel, em vinhetas ilustradas.

No que se refere ao teatro, as peças eram divididas em quadros coloridos e ilustrados que podiam ser recortados e agrupados em seqüências diferentes, gerando novas narrativas. Um exemplo é A chave mágica, publicada na edição de janeiro de 1908. Já a Sétima arte fazia-se presente com pequenos textos, trazendo fotos dos filmes que encantavam o público infantil nas matinês.

\section{O DIDATISMO E A INFORMAÇÃO}

Uma importante característica dessa revista foi o aspecto educacional, com sua proposição criativa já se colocando como uma intervenção decidida

10. Ibid.

11. O TICO-TICO: uma revista impressa na lembrança, op. cit. no processo educacional, baseada nos valores da classe média do País. Esse, talvez, seja o motivo de ela ter sido cultuada por várias gerações, que dela receberam ensinamentos morais e cívicos básicos para sua formação intelectual. Ela acompanhava um momento histórico marcado por preocupações com 
o desenvolvimento intelectual das crianças, que se deveriam transformar em pessoas íntegras, tementes a Deus e respeitadoras dos preceitos morais.

Foi nesse ambiente, espelhando os valores almejados pelas camadas dominantes da sociedade, que surgiu, cresceu e floresceu O Tico-Tico, baluarte da moral tradicional e do espírito positivista da chamada República Velha. Mesclava elementos de civismo e preceitos religiosos do catolicismo, religião dominante no País, os quais apareciam em várias seções da revista, como os contos infantis, as poesias patrióticas e as narrativas históricas.

Deve-se destacar que a revista foi eficiente no objetivo de trazer entretenimento e lazer às crianças. Por outro lado, ela não o fez de maneira inocente, pois buscava formar um determinado tipo de cidadão e louvar um padrão de comportamento: aquele que ajudaria a construir a sociedade imaginada pelos diretores da revista e pelas classes sociais que eles representavam. No dizer de Zita de Paula Rosa,

[...] construiu-se em torno de O TICO-TICO uma imagem que correspondia a um conjunto de representações projetado pelas classes privilegiadas e assimilado por setores das classes médias: a organização de uma sociedade modelar, dirigida pelos mais aptos, competentes e criativos e assistida em suas misérias e diferenças. Procurava-se, desse modo, transformar a visão constrangedora de um Brasil atrasado, subdesenvolvido, enfermo e repleto de analfabetos ${ }^{12}$.

O Tico-Tico envolveu-se também na campanha pela implantação do escotismo no País, entendendo que este defendia os valores éticos que a publicação preconizava. Teve cuidado especial na seleção dos passatempos e concursos e até mesmo na forma como eram redigidas as mensagens publicitárias, salientando o desenvolvimento sadio e livre de mazelas. Em todas essas áreas, os diretores buscaram incutir proposições moralistas, reforçando a linha pedagógico-moral da publicação. Essas proposições apareciam com destaque nas seções dedicadas a desenvolver um diálogo permanente com os leitores e que representaram uma verdadeira escola de disciplina, como as Lições de Vovô, a Correspondência do Dr. Sabetudo e a Gaiola d'O Tico-Tico.

As dimensões moral e educativa estiveram no cerne da revista, constituindo sua razão de ser. Tanto nos contos como nas histórias em quadrinhos, os desfechos deixavam lições e recriminavam comportamentos desviantes da norma aceita na sociedade: na história $O$ menino que montou o cachorro (publicada no primeiro número da revista), por exemplo, o garoto Tatá, que maltrata seu cão, é levado pela carrocinha. Esses aspectos foram assimilados pelos adultos, que viram nessa revista uma aliada para a formação dos jovens brasileiros e lhe deram apoio quase incondicional.

\section{ALMANAQUES E OUTROS TÍTULOS}

O sucesso de $O$ Tico-Tico levou à criação do Almanaque d'O Tico-Tico, edição anual de final do ano, com capa dura e o melhor material publicado na revista: histórias em quadrinhos, brinquedos para montar, páginas duplas e 
comunicação \& educação • Ano XIII • Número 2 • maio/ago 2008

quádruplas ilustradas e coladas manualmente, que podiam formar cenários diversos. O primeiro almanaque surgiu em 1906 (o Almanaque d'O Tico-Tico para 1907) e o último em 1957 (Almanaque d'O Tico-Tico para 1958), tendo, em média, 140 páginas.

Para concorrer com outras publicações voltadas ao público infantil, os editores de $O$ Tico-Tico resolveram diversificar seus títulos. Assim, em janeiro de 1950, foi lançada a revista mensal Tiquinho, com 32 páginas coloridas e destinada à criança em fase de alfabetização. Seu conteúdo, porém, pouco diferia do material editado em $O$ Tico-Tico: as histórias em quadrinhos eram feitas por Luiz Sá, Giselda Melo, Edmundo Rodrigues e Miguel Hochman. Tiquinho alcançou 137 edições e terminou no início da década de 1960.

Pensando nas meninas da mesma faixa etária, foi criada em abril de 1951 a Cirandinha, que trazia contos de fadas, histórias com personagens femininas, ilustradas por Luiz Sá, receitas, poesias e atividades consideradas importantes para a formação das mulheres. O título totalizou 59 edições.

Outra publicação derivada da revista foi Pinguinho, que surgiu em março de 1954 e teve apenas 27 números. Era destinada a crianças em idade pré-escolar, com textos curtos e muitas ilustrações. Da mesma forma que $O$ Tico-Tico, essas publicações ganharam almanaques anuais.

A Sociedade Anônima O Malho iniciou a publicação de edições educativas nos anos 1930, com a Coleção SETH, contendo temas referentes ao aprendizado da língua, à matemática, ao desenho e à história do Brasil e que era muito utilizada por professores. Na mesma época, a Biblioteca Infantil d'O Tico-Tico apresentava textos de Josué Montello, Olavo Bilac, Humberto de Campos, Juracy Camargo, entre outros. Ao longo da década de 1950 e no início dos anos 1960, a editora produziu edições temáticas educativas e cívicas, como Teatrinho na escola e a Edição patriótica d'O Tico-Tico.

\section{UMA VISÃO CRÍTICA}

Ao se refletir sobre a trajetória de uma publicação como a revista $O$ TicoTico, que durante 56 anos exerceu uma influência inquestionável na formação das crianças brasileiras, saltam à vista, naturalmente, seus aspectos positivos, que fizeram com que o título fosse, durante vários anos, modelo preponderante de publicação para a infância no País. No entanto, deve-se lembrar que essa revista também apresentou traços que poderiam ser vistos de forma não tão favorável, merecendo alguma reflexão por parte de todos aqueles que se debruçaram sobre ela.

Nenhuma produção é neutra. Filmes, desenhos animados, livros infantis ou revistas de histórias em quadrinhos dirigidos ao público infantil são produzidos a partir de uma imagem específica de criança que se deseja moldar. Essa revista não foge à regra. Muito mais do que outras, ela, por meio da abnegação de seus editores e colaboradores, buscou uma atuação determinista 
na sociedade da primeira metade do século XX, com o firme propósito de influenciar no desenvolvimento intelectual das crianças brasileiras, acompanhando o pensamento positivista corrente nas camadas pensantes do início do período. Dessa forma, pode-se dizer que os responsáveis pela publicação defendiam um tipo de revista que pudesse colaborar na futura integração da criança ao mercado produtivo, ajudando a formar adultos proativos, que acreditassem na força do trabalho e participassem em plenitude de um capitalismo em ascensão.

A revista $O$ Tico-Tico elegeu como seu público preferencial a criança de classe média, oriunda de uma família solidamente constituída, temente a Deus, respeitadora dos valores pátrios, matriculada em instituições educacionais formais, com uma inteligência superior à média e submissa aos preceitos morais predominantes na sociedade brasileira; ela assentou suas energias nos filhos da classe média urbana, pautando-se pelos interesses, desejos e gostos desse segmento social, dessa forma reforçando em suas páginas os modelos aceitáveis de comportamento que podiam colaborar para a permanência do padrão social vigente. Refletia, assim, uma concepção de infância caracterizada pela ingenuidade, em que meninos e meninas precisam ser guiados pela lucidez e sapiência dos mais velhos, evidenciando a tradição cultural brasileira do paternalismo em relação aos mais fracos, encontrada inclusive na relação do Estado com o povo humilde, que precisava ser protegido, doutrinado, conduzido pelas elites políticas e intelectuais.

Isso acontecia em relação a todos os aspectos importantes da vida social brasileira. No que se refere à questão racial, a revista reproduzia os estereótipos consagrados pela sociedade: os garotos negros, por exemplo, na maioria das vezes eram retratados como agregados de uma família branca de posses, para a qual realizavam diversas tarefas, sem ter direito a vínculos trabalhistas ou remuneração - sendo exemplo disso Benjamin, o garoto negro que acompanha as travessuras de Chiquinho -, ou , ainda, eram reproduzidos com a imagem-clichê do canibal africano, comum em quadrinhos e desenhos animados da época.

Por sua vez, as desigualdades sociais do País e a própria existência das chamadas classes populares explicavam-se de forma enviesada, sendo atribuídas a infortúnio pessoal, falta de dedicação ao trabalho ou impossibilidade/ incompatibilidade de seus membros para freqüentar os bancos escolares; eram compostas de indivíduos irremediavelmente presos à eterna condição de executores de serviços pesados, com remota expectativa de mudança social, sina da qual os leitores da revista poderiam escapar apenas se fossem estudiosos, diligentes, esforçados, prestativos e, acima de tudo, trabalhadores. Embora, em variadas ocasiões, o trabalho infantil seja louvado como uma atividade desejável e valorizado como exemplo de iniciativa pessoal e sucesso garantido, nem uma palavra foi jamais dirigida à denúncia de casos de exploração de menores pela então incipiente indústria têxtil nacional ou à utilização de crianças como fonte de recursos adicionais para seus progenitores. 
13. MERLO, Maria Cristina. O Tico-Tico: um século de histórias em quadrinhos no Brasil. Dissertação (Mestrado)Escola de Comunicações e Artes da Universidade de São Paulo, São Paulo, 2003

14. VERGUEIRO, Waldomiro. Origen, desarrollo y tendencias de las historietas brasileñas. Revista Latinoamericana de Estudios de la Historieta v. 4, n. 16, p. 195-196, 2004

15. O TICO-TICO: edição comemorativa do 50 응 aniversário, op. cit. comunicação \& educação • Ano XIII • Número 2 ・ maio/ago 2008

\section{DECLÍNIO E DESAPARECIMENTO DA REVISTA}

O reforço dos objetivos da publicação, expresso em editoriais, nos testemunhos de antigos leitores e nos conselhos do Vovô, ajudou a criar o mito das benesses de um modelo pedagógico baseado no respeito às leis $\mathrm{e}$ na defesa da moral e dos bons costumes. Ao mesmo tempo, essas atividades mantiveram a coerência da revista durante mais de cinco décadas ${ }^{13}$. No entanto, assim como garantiu a longevidade da publicação, essa coerência também representou o motivo de seu desaparecimento, em razão do desgaste e da perda do suporte a essa visão tradicionalista do desenvolvimento infantil pela sociedade brasileira.

Em 1934, no Rio de Janeiro, o Suplemento Infantil (depois, Juvenil) inaugurou uma nova fase das histórias em quadrinhos no Brasil, introduzindo no País o modelo norte-americano, em que se destacavam aventuras mirabolantes e personagens de intensa representação social. A nova publicação trazia um dos melhores momentos da história em quadrinhos norte-americana, com autores como Alex Raymond, Al Capp, Hal Foster, Lee Falk, entre outros ${ }^{14}$.

O sucesso do Suplemento abriu caminho para outras publicações no mesmo estilo. Em seguida, vieram as revistas de histórias em quadrinhos. A popularidade dessas novas publicações afetou a predominância de $O$ TicoTico, colocando um fim a seu reinado de mais de 30 anos. Os personagens ingênuos e bem-intencionados da revista foram substituídos no gosto popular por desbravadores de novos mundos, homens mascarados ou seres dotados de superpoderes.

Os editores tentaram uma reação à concorrência, incorporando ao título algumas séries de aventura dos quadrinhos norte-americanos. Autores brasileiros também foram chamados a trabalhar nessa linha de histórias, destacando-se Carlos Thiré, com Os legionários da sorte. Contudo, as mudanças na revista não perduraram. No início dos anos 1940, foram retomados seus propósitos originais, mantendo inalterado o âmago da publicação. Assim, manteve-se na categoria infantil didático-pedagógica, recusando modificações que pudessem levá-la ao encontro de uma nova geração de leitores e fazer frente ao novo modelo de publicação infanto-juvenil. Com isso, caminhou inexoravelmente para seu fechamento.

Em suas duas últimas décadas de existência, cresceram na revista $O$ TicoTico as páginas de entretenimento, que deixavam de lado o desenvolvimento de atividades motoras ou o desafio à curiosidade intelectual dos leitores. Nesta última fase, destacam-se as piadas, anedotas e histórias mudas puramente humorísticas, que, quase sempre, constituíam seções fixas, como Cinco minutos de riso ou Fique triste se puder.

Em 1955, os editores da revista lideraram uma série de comemorações pelo seu cinqüentenário. Um número especial comemorativo foi publicado (Figura 4), com depoimentos de personalidades da vida política e cultural brasileira, realizando uma avaliação emotiva do percurso da revista ${ }^{15}$. Ainda 


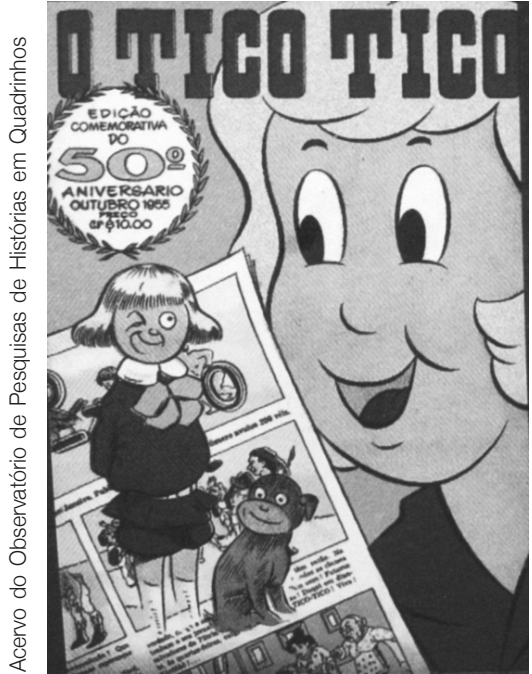

Edição comemorativa do 50aaiversário. assim, apesar das manifestações de apoio, não se podia esconder o fato de que era uma publicação ultrapassada, viva apenas pelas lembranças daqueles que com ela haviam convivido em sua infância.

A chegada da televisão ao País, em 1950, também concorreu para o golpe de misericórdia em O Tico-Tico. Sem condições de concorrer com a nova mídia nem disposição para se modernizar, ela se esvaiu no início da década de 1960. Depois da interrupção da revista, a editora $\mathrm{O}$ Malho, então com nova denominação comercial, publicou várias coleções de livros. Em geral, com reaproveitamento dos textos publicados na revista, atualizados para o novo público. Isto perdurou até 1977, quando essas atividades editoriais cessaram.

\section{A HERANÇA DE O TICO-TICO}

A proposta editorial da revista manteve-se praticamente inalterada durante toda a sua existência. A imagem de uma publicação benéfica, em que apenas bons ensinamentos e diversão sadia podiam ser encontrados, foi largamente incentivada por seus editores, que se mantiveram fiéis à sua postura inicial. Ou seja, recusavam-se a reconhecer que tal modelo de revista infantil, na qual até mesmo os aspectos lúdicos deviam se subordinar a objetivos didático-pedagógicos, havia se tornado totalmente anacrônico. A revista pagou caro por isso, não sobrevivendo à década de 1960, em que os valores tradicionais que ela preconizava passaram, cada vez mais, a ser objeto de constante questionamento.

A celebração de 100 anos do início da publicação da revista O Tico-Tico, ocorrida em outubro de 2005, possibilitou uma reflexão sobre seu impacto na vida do País. Mais que simplesmente desfilar panegíricos ao título, a comemoração permitiu que fosse realizada uma análise crítica sobre o potencial de publicações desse tipo para a vida cultural brasileira. Nesse sentido, os diversos artigos a respeito do título e os dois livros lançados nesse evento $^{16}$ evidenciaram a importância da revista. Mais que uma lembrança, O Tico-Tico tornou-se uma lenda no Brasil, ajudando, ainda que utilizando uma postura pedagógica conservadora e moralista - que visava reforçar os comportamentos socialmente aceitos no período -, a quebrar algumas barreiras em relação aos produtos quadrinhísticos no País. E esta, talvez, seja uma contribuição ainda não devidamente aquilatada por estudiosos e aficionados brasileiros.

16. Ver AZEVEDO, Ezequiel de. O Tico-Tico: cem anos de revista. São Paulo: Via Lettera Editora, 2005; VERGUEIRO, Waldomiro; SANTOS, Roberto Elísio dos (Orgs.). O Tico-Tico: centenário da primeira revista de quadrinhos do Brasil. São Paulo: Opera Graphica, 2005. 
comunicação \& educação • Ano XIII • Número 2 - maio/ago 2008

\section{REFERÊNCIAS BIBLIOGRÁFICAS}

AZEVEDO, Ezequiel de. O Tico-Tico: cem anos de revista. São Paulo: Via Lettera Editora, 2005.

CIRNE, Moacy. História e crítica dos quadrinhos brasileiros. Rio de Janeiro: Ed. Europa/Funarte, 1990.

COTRIM, Álvaro. Era uma vez um... Tico-Tico. Cultura, Brasília, v. 4, n. 15, dez. 1974.

MELO, José Marques de. Para uma leitura crítica da comunicação. São Paulo: Paulinas, 1985.

MERLO, Maria Cristina. O Tico-Tico: um século de histórias em quadrinhos no Brasil. Dissertação (Mestrado) - Escola de Comunicações e Artes da Universidade de São Paulo, São Paulo, 2003.

MOYA, Álvaro de. O Tico-Tico: marco de nossas publicações infantis. In: VaptVupt. São Paulo: Clemente \& Germani Editora, 2003.

O TICO-TICO: edição comemorativa do $50^{\circ}$ aniversário. Rio de Janeiro: O Malho, 1955.

O TICO-TICO: uma revista impressa na lembrança. São Paulo: SESC, 20032004.

ROSA, Zita de Paula. O Tico-Tico: meio século de ação recreativa e pedagógica. Bragança Paulista: EDUSF, 2002.

SODRÉ, Nelson Werneck. História da imprensa no Brasil. 3. ed. São Paulo: Martins Fontes, 1983.

VERGUEIRO, Waldomiro. Origen, desarrollo y tendencias de las historietas brasileñas. Revista Latinoamericana de Estudios de la Historieta, v. 4, n. 16, 2004.

VERGUEIRO, Waldomiro; SANTOS, Roberto Elísio dos (Orgs.). O Tico-Tico: centenário da primeira revista de quadrinhos do Brasil. São Paulo: Opera Graphica, 2005. 